\title{
Stability Monitoring and Analysis of High and Steep Slope of a Hydropower Station
}

\author{
Guangcheng Shi, ${ }^{1,2}$ Gongkai Gu, ${ }^{3}$ Hua Zhou, ${ }^{4}$ Zhigang Tao ${ }^{1},{ }^{1,2}$ Hongyue Pan, ${ }^{3}$ \\ and Ting Tang 5 \\ ${ }^{1}$ State Key Laboratory for Geomechanics and Deep Underground Engineering, China University of Mining and Technology-Beijing, \\ Beijing 100083, China \\ ${ }^{2}$ School of Mechanics and Civil Engineering, China University of Mining and Technology, Beijing 100083, China \\ ${ }^{3}$ China Three Gorges Construction Management Co., Ltd., Beijing 100038, China \\ ${ }^{4}$ Changjiang Survey, Planning, Design and Research Co. Ltd., Wuhan 430010, China \\ ${ }^{5}$ Yangtze Ecology and Environment Co., Ltd., Wuhan 430062, China
}

Correspondence should be addressed to Zhigang Tao; taozhigang@263.net

Received 24 June 2020; Revised 25 July 2020; Accepted 29 August 2020; Published 6 October 2020

Academic Editor: Qian Yin

Copyright (C) 2020 Guangcheng Shi et al. This is an open access article distributed under the Creative Commons Attribution License, which permits unrestricted use, distribution, and reproduction in any medium, provided the original work is properly cited.

\begin{abstract}
Slope deformation and failure are major challenges for hydropower station engineering. Taking the left bank slope at the exit of the flood discharge tunnel of the Wudongde Hydropower Station in China as an example, the deformation mechanism of the highsteep rock slope was studied. The height of the slope is about $200 \mathrm{~m}$, which is affected by slope excavation, rainfall, and atomized rain. The results of multipoint displacement meters, surface deformation monitoring, and anchoring stress meters showed that the deformation and deformation rate of the slope have increased dramatically. Through the comprehensive analysis of the slope, it is found that the overall lithology of the slope is poor, the excavation disturbance causes the redistribution of the stress in the slope, and the excavation surface is relatively steep, which provides space for the deformation of the slope rock mass. Unloading relaxation leads to a large number of new fissures in the slope rock mass. These new fissures and fault fracture zones provide convenient conditions for rainfall and atomized rain infiltration. The rainwater infiltrated along the slope surface, formed the seepage field in the slope body, and weakened the rock-soil mass parameters. Meanwhile, saturated runoff is formed on the slope, causing large deformation of the slope rock mass. However, the migration of water in the slope has a time effect, and its influence on the stability of the slope also has a time effect. It is difficult for traditional monitoring methods to monitor the resulting changes in internal sliding force of the slope. Therefore, a remote monitoring and early warning system for landslide anchor cable force was introduced to monitor the slope stability changes caused by the impact of water flow and rainfall infiltration, which provided a reasonable and scientific reference for subsequent slope construction.
\end{abstract}

\section{Introduction}

The large deformation of high and steep slopes leads to widespread and catastrophic geological hazards. The high and steep slopes of a hydropower station are among the most common and dangerous morphologies. The construction and operation of the plant can trigger or reactivate such morphologies and significantly threaten human lives and properties $[1,2]$. Consequently, significant efforts have been made to monitor such slopes and to design and implement effective countermeasures.
At present, although brilliant achievements have been made in the excavation disturbance [3-5] and rainwater seepage [6-8] of high and steep slope projects, they have also paid a heavy price. Deformation and destruction phenomena of different degrees and scales will affect the construction of high slope projects in water conservancy and hydropower projects. For example, the left and right abutment slopes of Miaowei Hydropower Station have undergone significant deformation during the excavation process. With the progress of the excavation, five significant deformations occurred 


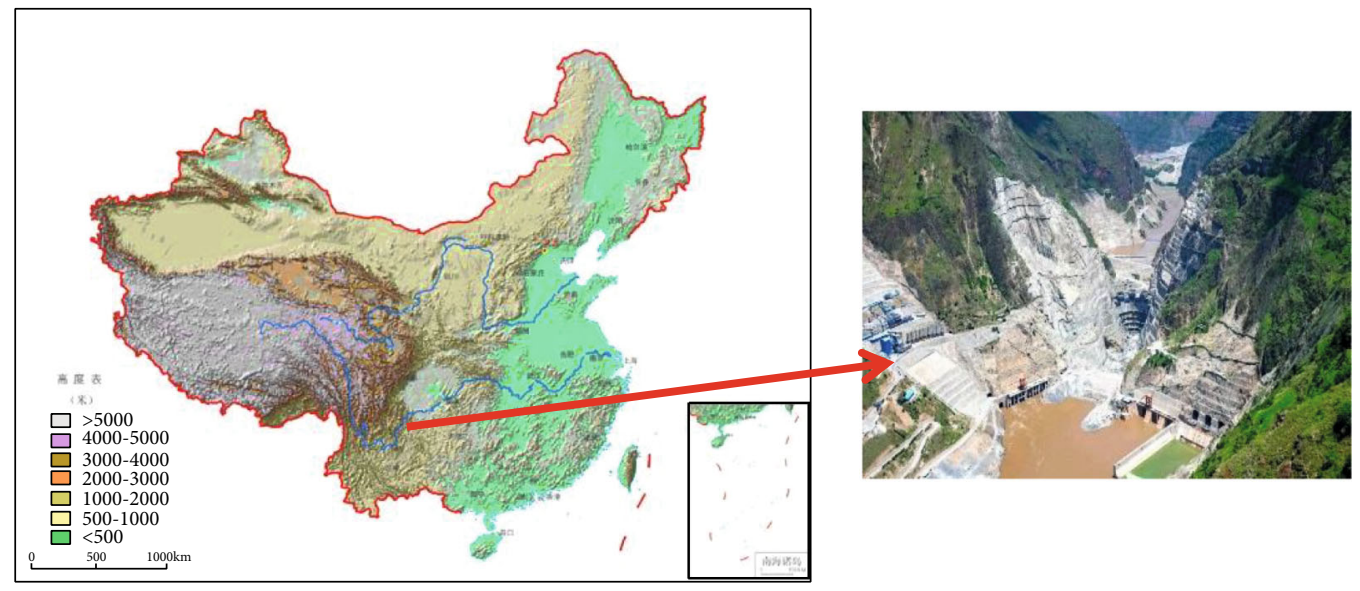

Figure 1: Geographical location of Wudongde Hydropower Station.

on the left abutment slope, and a landslide occurred on the right abutment slope from $1340 \mathrm{~m}$ to $1384 \mathrm{~m}$, severely affecting the construction $[9,10]$. Many scholars have analyzed the deformation mechanism of high steep slopes under excavation conditions. In order to analyze the loosening characteristics of columnar jointed basalts, the temporal-spatial evolution of the loosening depths and degrees of the leftbank slope were investigated through single-hole acoustic wave tests and visual inspections with borehole cameras. The tests were carried out in the columnar jointed basalt test section of the left bank dam foundation of Baihetan hydropower station [11-13]. For high dam projects with characteristics of high water head, large flood discharge, and narrow canyon, there is a class of rock slope instability problems that is induced by rainfall and flood discharge atomized rain. Here, atomized rain refers to the rain produced by the discharge of flood from high dams. Due to rainfall infiltration being the most frequent triggering factor for natural high steep rock slope failure, substantial research has been carried out to study the failure mechanisms of rainfall-induced landslides. This class of rock slope stability problems is mainly affected by the mechanical parameter reduction of structural planes and the internal pore water pressure [14-22].

The complex internal factors such as lithology and rock mass structure of the high-steep rock slope [23-25] and the external factors such as construction disturbances and heavy rain may change the slope during construction and operation. Many scholars have carried out microscopic experiments on rock crack growth to better understand the process and mechanism of rock slope failure, obtaining interesting research results [26-32]. In order to reflect the real mechanical effect of the rock mass and to ensure a stable state of the slope, slope monitoring projects are needed. Nowadays, many kinds of slope stability monitoring technologies and methods exist, from the traditional total station, the inclined pipe, the pressure gauge, the rain gauge, and the displacement meter [33] to the new type of the GPS [34], the laser range finder [35], the synthetic aperture radar [36], the ground-based interferometric radar [37], and the geological radar [38].
Research on slope stability monitoring and early warning technology is one of the leading research topics in the field of geotechnical engineering, and many scholars have investigated it. An early warning monitoring system is established to collect data such as seismic waves, pressures, and groundwater levels and activated the early warning signal when the instrument produced a signal outside the range [39], taking the excavation of the high slope on the left bank of Jinping I Hydropower Station as the research object. The monitoring results of the deformation of the graphite rod convergence meter of the flat hole, the horizontal observation of the valley width, the load of the anchor cable, and the deformation of the shear hole were comprehensively analyzed. Furthermore, the deformation law of the slope rock mass was obtained [40].

Based on the mechanics of the sliding body, sliding bed, and theory of monitoring anchor cable interaction as the theoretical basis, the principle of mechanical monitoring of the relative motion state of a sliding body and a sliding bed was put forward. Moreover, the multifactor monitoring was changed into single sliding force mechanical quantity monitoring, and the relationship between the sliding force and the monitoring pretightening force was given [41, 42]. Based on the above principles, a remote monitoring and forecasting system for landslide geological hazards was developed for the real-time remote monitoring of dynamic changes of disturbance forces. The proposed approach overcomes the bottleneck of conventional deformation monitoring and realizes monitoring and early warning of deep sliding forces [43-45].

This study takes the slope of Wudongde Hydropower Station as the research object and analyzes the slope deformation mechanism caused by excavation and rainwater infiltration through field investigation and slope deformation monitoring data. In addition, in order to better monitor the large deep deformation of the slope rock mass caused by the infiltration of atomized rain, a remote monitoring and early warning system for the force of the anchor cable is introduced. The monitoring system will provide a reasonable and scientific reference for subsequent slope construction. 


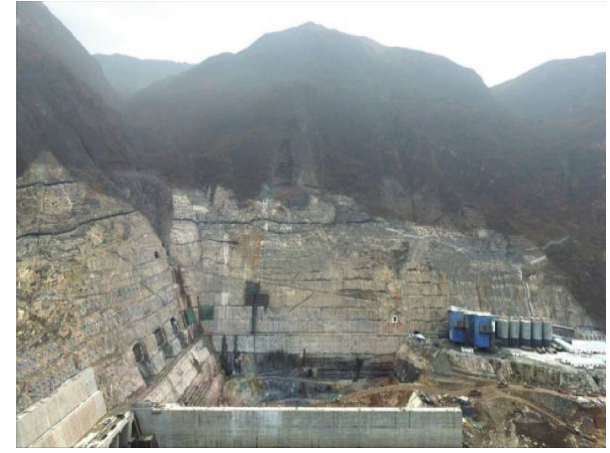

FIGURE 2: Engineering slope.

\section{Engineering Geology}

2.1. Slope Engineering. Wudongde Hydropower Station is the first of the four cascade hydroelectric power stations in the lower reaches of the Jinsha River, which is of great significance to China's hydropower development. The plant is located on the Jinsha River at the junction of Luquan County, Kunming, Yunnan Province, and Huidong County, Liangshan Prefecture, Sichuan Province (Figure 1). The elevation of the left side slope of the outlet of the spillway tunnel of the hydropower station is more than $1070 \mathrm{~m}$, which is a naturally exposed rock slope. The altitude from $1070 \mathrm{~m}$ to $1760 \mathrm{~m}$ is a steep slope with an average inclination of $55^{\circ}$. Before the excavation of the slope, the area below $1070 \mathrm{~m}$ elevation is a gentle slope formed by the Huashangou deposit, with an inclination of $10^{\circ} \sim 35^{\circ}$. The artificial slope structure is a transverse slope. The highest elevation line is about $970 \mathrm{~m}$, the excavation of the plunge pond foundation corridor is of $786.5 \mathrm{~m}$ elevation, and that of the artificial slope is $183.5 \mathrm{~m}$.

2.2. Stratigraphic Structure and Lithology. The engineering slope and natural slope above $925 \mathrm{~m}$ elevation are sedimentary caprock strata. The strata trending NNW-SSE dipping at an angle of $30^{\circ}$ toward $\mathrm{E}$, and the angle between the strike of the stratum and the strike of the slope is about $3^{\circ} \sim 37^{\circ}$, forming a gently inclined reverse slope. The engineering slope below $925 \mathrm{~m}$ elevation consists of folded strata that trend SW-NE and dip about $80^{\circ}$ toward S. The strike of left side slope of the exit of the flood discharge tunnel is $193^{\circ}$, and the angle between the strike of the rock stratum and the slope forms a steep, transverse slope of about $57^{\circ} \sim 83^{\circ}$ (Figure 2). The strata exposed before the excavation are the quaternary Huashangou accumulation body and the folded basement snowfall group, the sedimentary caprock Guanyinya Formation, and the Dengying Formation (Figure 3).

\subsection{Hydrometeorological Conditions. Wudongde Hydro-} power Station is located in the dry and hot valley of Jinsha River. The average annual precipitation is $600 \mathrm{~mm}-800 \mathrm{~mm}$, the rainfall is relatively concentrated, and the precipitation from June to October accounts for $81 \%$ of the annual precipitation. The average maximum temperature in the study area is $42.7^{\circ} \mathrm{C}$, and the minimum temperature is $-5.8^{\circ} \mathrm{C}$; the difference between the two is as high as $48.5^{\circ} \mathrm{C}$. The average max-

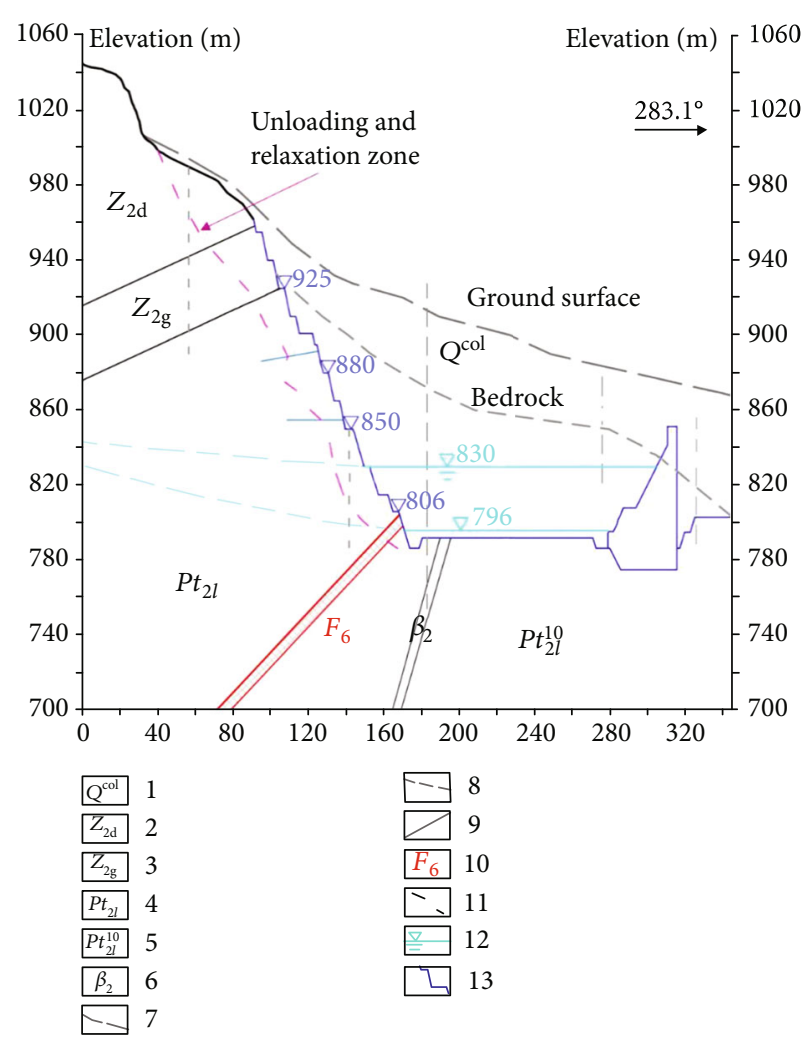

Figure 3: Engineering geology map of the slope. 1: collapse accumulation layer; 2: Dengying Formation grey to light grey thick dolomite; 3: Guanyinya group gray thin layer dolomite sandwich, ultrathin shale; 4: gray thin layer dolomite (specifically refers to the falling snow group stratum in the downstream of the Huashangou fault on the left bank); 5: gray interbedded with thin limestone; 6: diabase; 7: original terrain; 8: bedrock surface; 9: lithology boundary; 10: faults and numbers; 11: lower limit of relaxation zone of artificial slope; 12: groundwater level line; 13: designed excavation line.

imum ground temperature is $72.4^{\circ} \mathrm{C}$, and the minimum ground temperature is $-5.3^{\circ} \mathrm{C}$; the difference between the two is as high as $77.7^{\circ} \mathrm{C}$. The average maximum temperature in the study area is $42.7^{\circ} \mathrm{C}$, and the minimum temperature is $-5.8^{\circ} \mathrm{C}$; the difference between the two is as high as $48.5^{\circ} \mathrm{C}$. The average maximum ground temperature is $72.4^{\circ} \mathrm{C}$, and the minimum ground temperature is $-5.3^{\circ} \mathrm{C}$; the difference between the two is as high as $77.7^{\circ} \mathrm{C}$. This large temperature difference is beneficial to accelerate the physical weathering of the rock mass, especially after the rain and atomized rain infiltrate the slope rock mass, causing a large range of relaxation deformation on the rock mass surface in the study area.

There is a waterfall at the junction of the front side slope and the left side slope at the exit of the spillway tunnel, and the rainy season has a large amount of water. In addition, after the spillway is put into use, the two will produce strong atomized rain around the water cushion pond. Atomized rain often forms at the lower part of the slope. Perennial atomized rain will have a serious impact on the slope. The brown-yellow rusting phenomenon appears locally on the slope surface, which is caused by the Fe ions in the unevenly distributed pyrite in the rock layer near the unconformity 


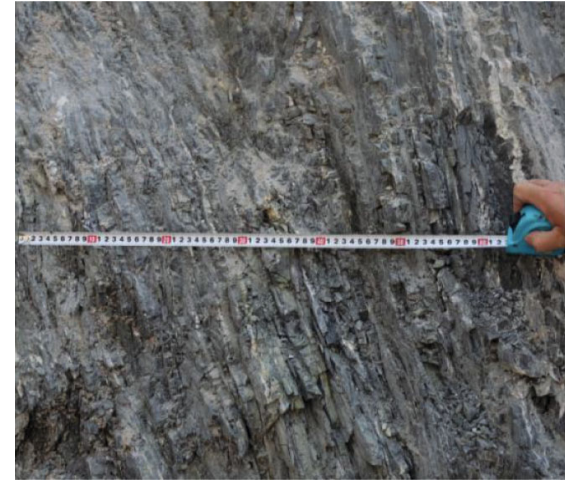

(a) Weakly weathered thin-layered limestone

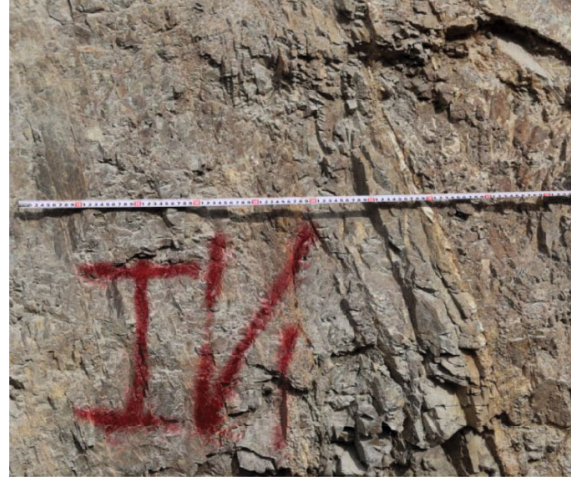

(b) Weakly weathered thin-layered dolomite

FIgURE 4: Typical rock mass of slope.

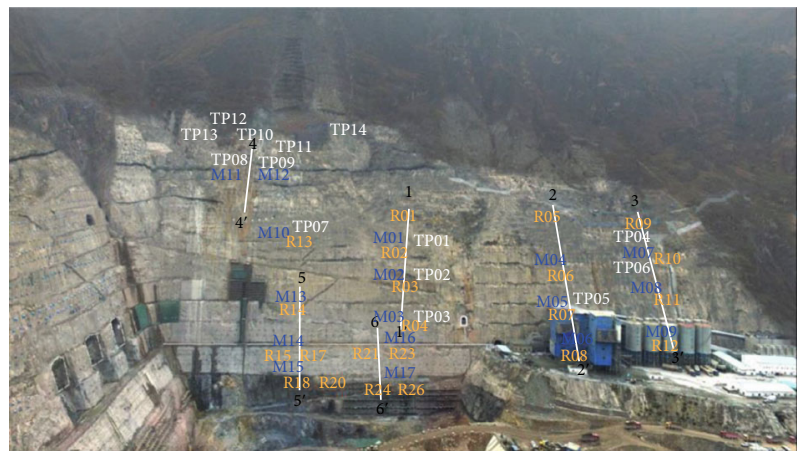

FIGURE 5: Distribution map of deformation monitoring points on the slope.

contact surface in the dam site, which oozes with water after oxidation and stains the concrete on the slope surface.

2.4. Engineering Geological Defects. The primary engineering geological defects revealed during the excavation of the slope include blocks, the fracture of the slope, the Huashangou fault $\left(F_{6}\right)$, and the poor quality of the rock mass.

2.4.1. Block. A total of 213 blocks was found on the surface of the slope. There were 153 blocks with a volume of less than $100 \mathrm{~m}^{3}$, 54 blocks with a volume between $100 \mathrm{~m}^{3}$ and $1000 \mathrm{~m}^{3}$, and six blocks with a volume between $1000 \mathrm{~m}^{3}$ and $10000 \mathrm{~m}^{3}$, which accounted for $71.9 \%, 25.3 \%$, and $2.8 \%$, respectively. The maximum bulk volume was about $4691 \mathrm{~m}^{3}$. Among them, there were 12 stable blocks, 187 blocks with poor stability, and 14 blocks with the worst stability. The buried depth varied about from $2 \mathrm{~m}$ to $5 \mathrm{~m}$, and the deepest was block found at about $29 \mathrm{~m}$.

2.4.2. Fracture of Slope. The on-site geological investigation showed that the fracture of the slope surface was not developed. The excavation of the engineering slope revealed a strike of cracks at $240^{\circ} \sim 310^{\circ}$ with an angle of $40^{\circ} \sim 60^{\circ}$. The crack surface was generally straight and rough, mostly with mud and calcium, and only a few was filled with debris and mud. The extension of cracks was about $5 \sim 10 \mathrm{~m}$. Only six fractures were longer than $20 \mathrm{~m}$, and the longest was about $37 \mathrm{~m}$. Most fracture surfaces were straight, rough, and mostly closed or slightly stretched, with calcium membrane or mud calcium membrane attached to the surface.

2.4.3. Fault. Huashangou fault $\left(F_{6}\right)$ is a large-scale geological structure of the entire slope. The strike of the fault was E-W, with an inclination angle of $70^{\circ}-75^{\circ}$ and trending SE. It intersects with the river valley at an angle of about $60^{\circ}$. It is a normal fault and cuts through the sedimentary caprock, and the vertical offset is about $420 \mathrm{~m}$. The fault through the slope, the plunge pool, and the tail drain guided the wall foundation. The $F_{6}$ was $3 \sim 8 \mathrm{~m}$ wide, mainly composed of clastic rock. Plasticized mudcracks or debris were found near the fault.

2.4.4. Poor Rock Mass Quality. The overall quality of the rock mass on the left side of the outlet of the spillway tunnel is poor, mainly grades IV1 to IV2, which are mainly distributed with weakly weathered thin-layered dolomite and limestone (Figure 4). The structural plane is dominated by layers, with microcracks developed, the layers are mostly straight and rough, filled with muddy calcareous, and the cracks are often attached with muddy calcium film, and the erosion and weathering along the structural plane are intensified.

\section{Deformation Monitoring Results}

The fault $F_{6}$ runs through the entire slope, and the rock mass of the fault fracture zone is very poor. At the same time, the slope has a series of isolated blocks and surface cracks. The existence of these geological defects seriously affects the stability of the slope. Moreover, frequent excavation disturbances cause severe unloading and relaxation of the slope, which leads to the extension and expansion of surface cracks into the rock mass. These geological defects and newly created fissures in the relaxation area will provide convenient conditions for the infiltration of rainwater and atomized rain, thereby increasing the effect of hydrostatic pressure in the fissure on the rock mass, accelerating the physical and chemical action of water on the rock mass structural plane, leading to the overall decline in rock mass quality, and ultimately leading to the deformation of the slope. Therefore, it was chosen as the main monitoring area for the slope project. 


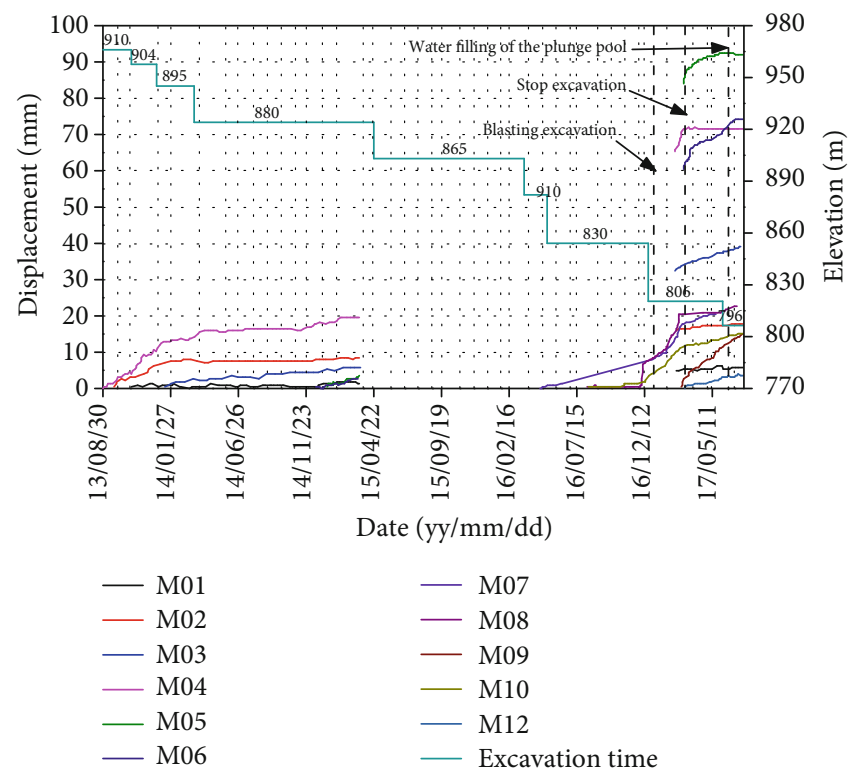

FIGURE 6: Relationship between the deformation of the multipoint displacement meter and the excavation process.

According to the different monitoring objects and monitoring depths, slope monitoring can be divided into appearance deformation monitoring, shallow deformation monitoring, and deep deformation monitoring. According to the characteristics of the project, six deformation monitoring sections (i.e., sections $1-1^{\prime}, 2-2^{\prime}, 3-3^{\prime}, 4-4^{\prime}, 5-5^{\prime}$, and $6-6^{\prime}$ ) were arranged on the slope. At the same time, 14 apparent monitoring piers, 17 sets of multipoint displacement meters, and 26 anchor stress meters were deployed (Figure 5).

3.1. Monitoring Results of Multipoint Displacement Meter. Seventeen sets of multipoint displacement meters, numbered M01 M17, were arranged on the slope. They were all placed at the downstream of $F_{6}$ and divided into two monitoring areas according to the structural characteristics of the slope. Among them, 11 sets were arranged between $F_{6}$ and the rear edge slope of the concrete system of $850 \mathrm{~m}$ elevation. Six sets were placed at the rear edge slope of the concrete system with an elevation of $850 \mathrm{~m}$. The monitoring depth was about $30 \mathrm{~m}$. Figure 5 shows the layout location. The monitoring time of each multipoint displacement meter is different, and the earliest time is May 5, 2013. Due to factors such as instrument failure and on-site environment, some data are missing. The whole process monitoring curve of the cumulative displacement of the multipoint displacement meter and the orifice is shown in Figure 6 and Table 1.

3.1.1. Cumulative Deformation. According to the analysis of the monitoring data in Table 1 and Figure 6, as of August 10,2017 , the cumulative deformation of the orifices of 13 multipoint displacement meters is less than $25 \mathrm{~mm}$, accounting for $76.5 \%$ of all monitoring points. The deformation of one monitoring point is $38.86 \mathrm{~mm}$, and that of three monitoring points is above $71 \mathrm{~mm}$. Among them, the monitoring point with the most considerable deformation is $\mathrm{M} 11$, at $986.8 \mathrm{~m}$ elevation, and the deformation is $92.15 \mathrm{~mm}$. The parts with large local deformation monitored by multipoint displacement meter are mainly located at section $4-4^{\prime}$ of the slope, that is, 920 990 $\mathrm{m}$ high near the ridge-shaped terrain, and close to the fault $F_{6}$. This data suggests that the slope unloading disturbance and fault structure affect the area significantly. The parts with small deformation monitored by the multipoint displacement meter are located near sections 2-2 and 3-3. That means they are at the trailing edge slope of $850 \mathrm{~m}$ elevation concrete system, suggesting a lighter effect of the excavation of the project on this part of the slope.

3.1.2. Deformation Depth. From Figure 6 and Table 1, among the 17 multipoint displacement meters, except for M11 and M03, the multipoint displacement meters at these two monitoring points show that there is still a large deformation at a depth of $30 \mathrm{~m}$ horizontally (note that the deformation at the monitoring depth of $30 \mathrm{~m}$ at both points is more significant than that at $20 \mathrm{~m}$, which are abnormal data). The data from the remaining 15 sensors prove that the slope rock mass at the distance of $30 \mathrm{~m}$ from the slope surface does not deform or deforms very little. Therefore, the excavation disturbance at the left side slope at the outlet of the spillway tunnel deforms the rock mass for a depth of about $20 \sim 30 \mathrm{~m}$.

3.1.3. Deformation Rate. The deformation rate of the slope rock mass can be divided into three stages, namely, deformation intensification stage, deformation slowdown stage, and deformation convergence stage (Figure 6).

The first stage is the deformation intensification stage. The deformation process of monitoring curves recorded by monitoring points M13, M14, and M16 reveals that the deformation aggravation occurs between December 24, 2016, and March 25, 2017. This period corresponds to the start and stops of blasting excavation of the slope below $830 \mathrm{~m}$. The second stage is the deformation slowdown stage that happened after the site stopped blasting excavation on March 25, 2017. The third stage is the deformation convergence stage. Among the 17 multipoint displacement meters, 


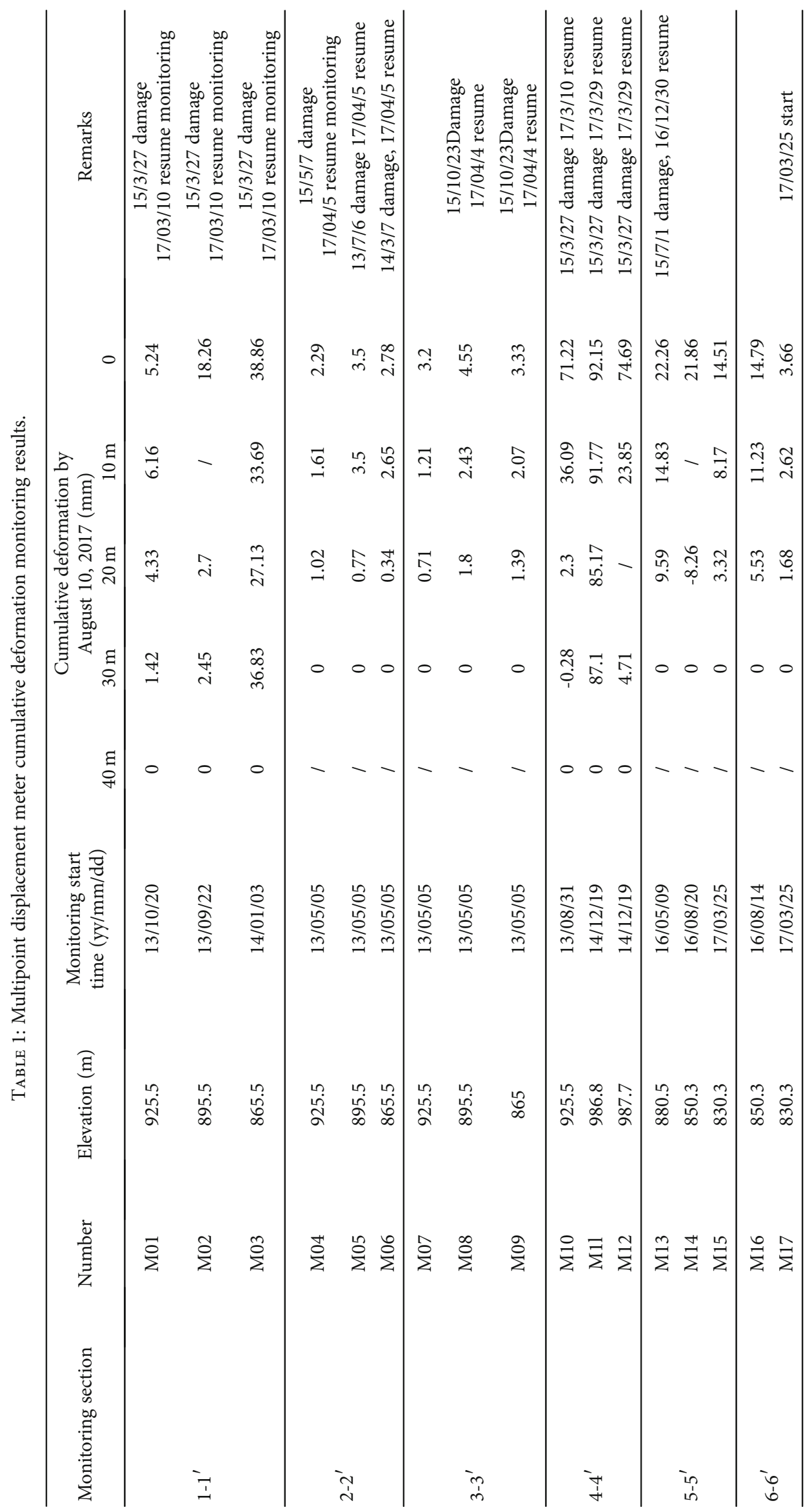




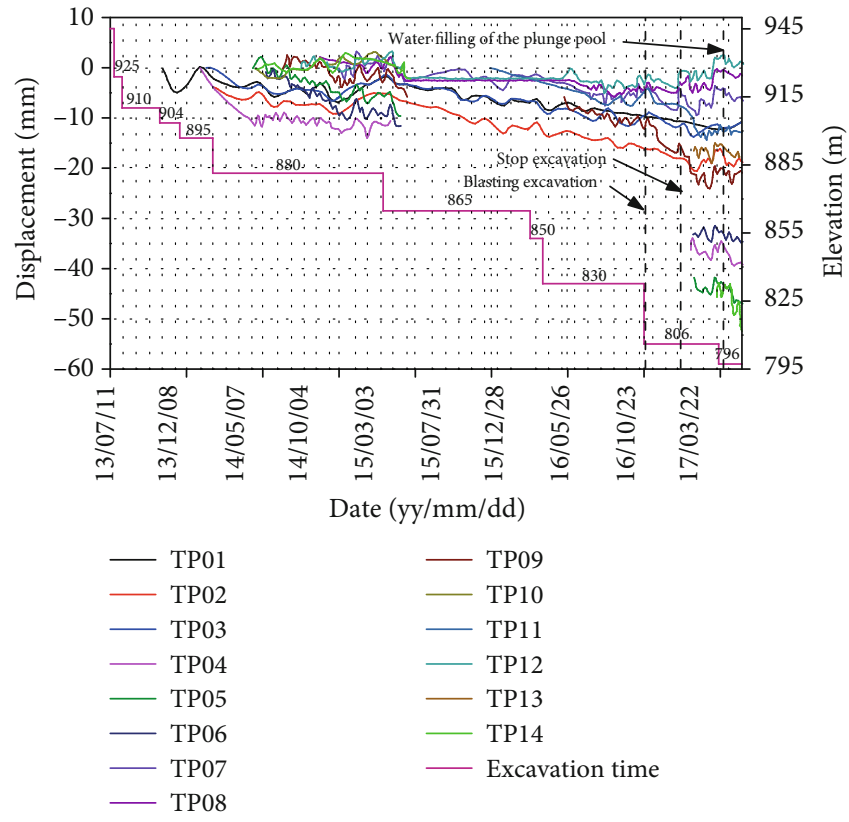

(a) Total slope deformation in the $X$ direction

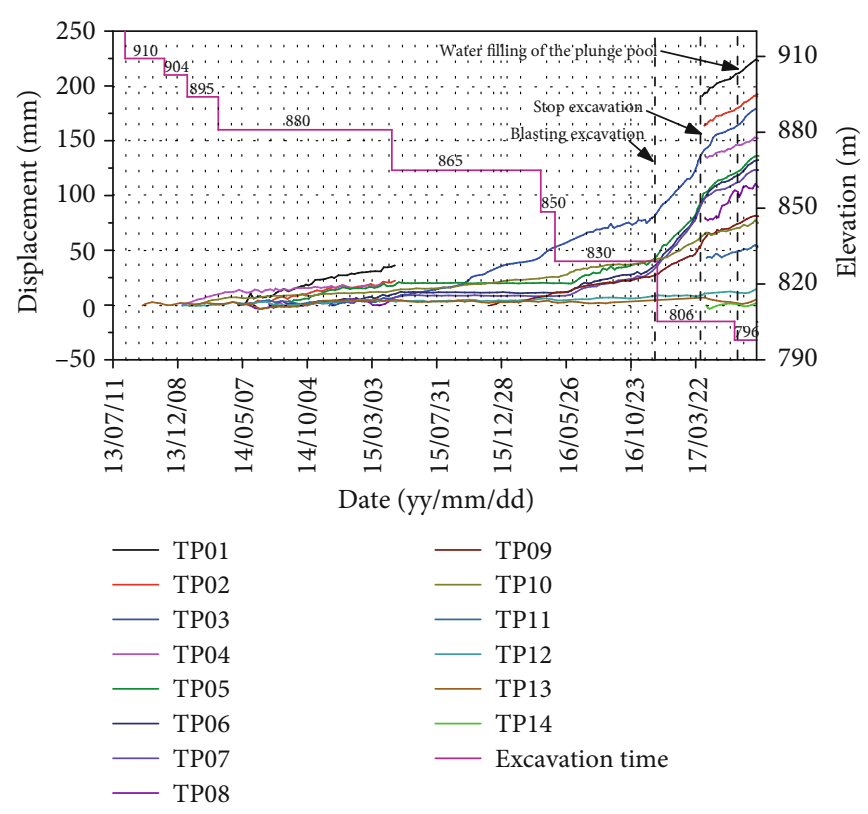

(b) Total slope deformation in the $Y$ direction

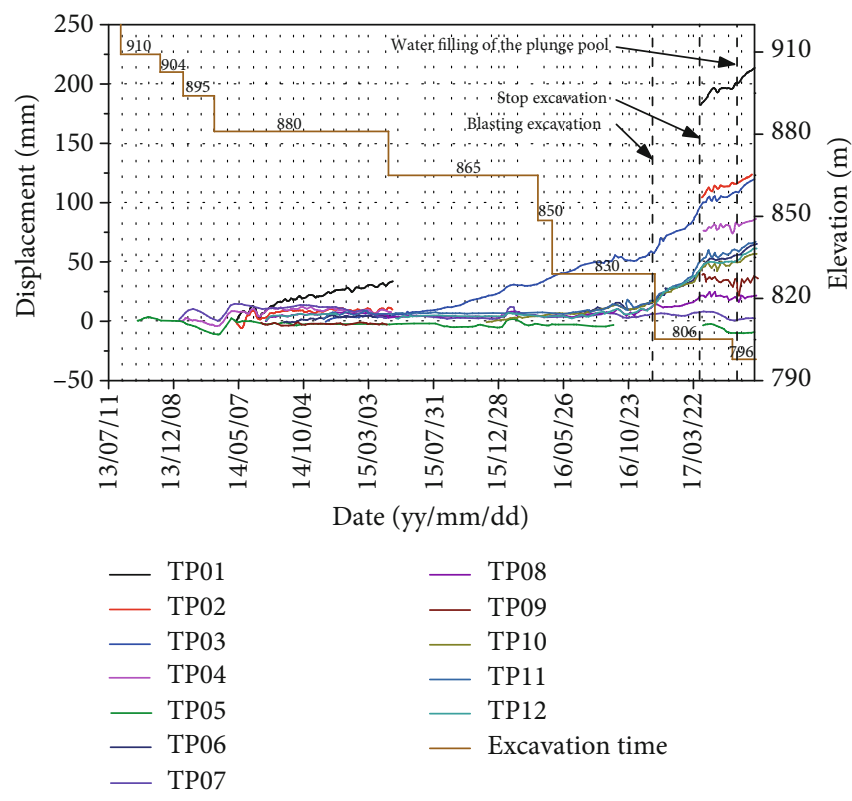

(c) Total deformation of slope in the $Z$ direction

FIgURE 7: Comparison curve between the total deformation of apparent monitoring and the excavation process.

the time points of convergence of each point are quite different. Most of them gradually converge about half a month after stopping blasting excavation, that is, in the middle of April 2017. The convergence time of monitoring points M12 near the ridge terrain and M15 near the fault $F_{6}$ are the latest, while the convergence time of monitoring points M04 M09 at the rear edge of a concrete system is earlier. On June 24, 2017, after the plunge pool was filled with water, the deformation rate of the slope was temporarily unchanged. In summary, after stopping the blasting excavation, all the deformation monitoring data of multipoint displacement meters tend to converge.
3.2. Apparent Deformation Monitoring Results. The 14 apparent deformation monitoring piers TP01 TP14 were all arranged downstream the fault $F_{6}$. Eleven piers were arranged between the fault $F_{6}$ and the rear edge slope of the concrete system at $850 \mathrm{~m}$ elevation; three were on the rear edge slope of the concrete system (Figure 5). Figure 7 compares the monitored total apparent deformation with the development of the excavation process. The horizontal deformation to the downstream of the river is the positive direction of $X$, and the upstream is the negative direction. The horizontal deformation to the outside of the slope is the positive direction of $Y$, and the deformation into the slope is the 


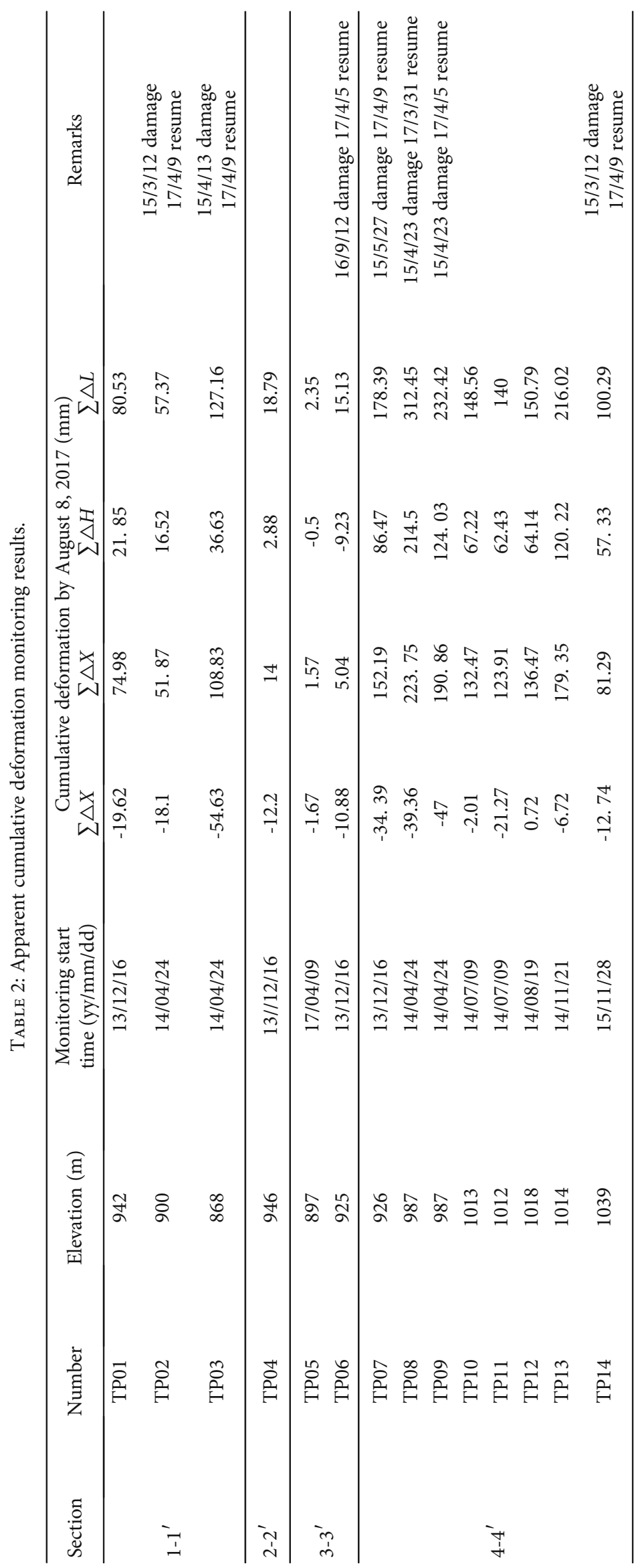




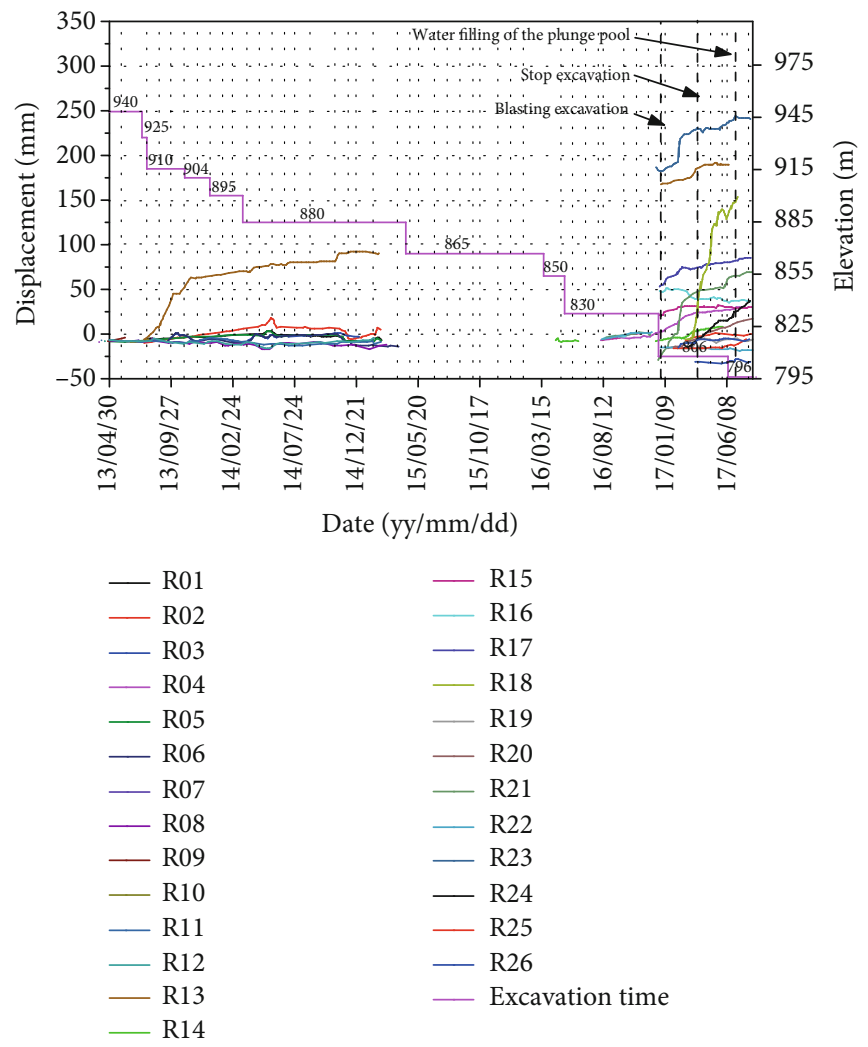

Figure 8: Comparison curve between the stress change of anchor stress meter and the excavation process.

negative direction. The vertical downward deformation is the positive direction of $H$, and the upward direction is the negative direction. The initial monitoring time of the apparent monitoring point was September 16, 2013. However, due to the influence of the on-site environment and equipment, only TP01, TP04, and TP10 TP14 recorded a relatively complete slope deformation process.

3.2.1. Cumulative Deformation. The deformation components of the apparent monitoring piers suggest that almost all the deformations in the river direction point to the upstream, and the cumulative deformation in this direction is the smallest, i.e., 8 to $23 \mathrm{~mm}$. Moreover, the monitoring point with the most significant cumulative deformation of $54.63 \mathrm{~mm}$ is TP03, located at $868 \mathrm{~m}$ elevation. The cumulative deformation of all monitoring points to the outside of the slope is generally between 50 and $140 \mathrm{~mm}$. The monitoring point with the most considerable cumulative deformation of $223.75 \mathrm{~mm}$ is TP08 at $987 \mathrm{~m}$ elevation. The monitoring points with large cumulative deformation after the excavation of the entire slope are higher than $980 \mathrm{~m}$, i.e., they are located in the local ridge-like terrain of the slope. Excavation and unloading affect these monitoring points significantly. The cumulative vertical deformation of most monitoring points is between 14 and $80 \mathrm{~mm}$; the monitoring point with the most substantial deformation (TP08) is at $987 \mathrm{~m}$ elevation; and the cumulative deformation is $214.5 \mathrm{~mm}$. There are two monitoring points with a deformation greater than $100 \mathrm{~mm}$, all of which are located above $980 \mathrm{~m}$ elevation. According to the apparent monitoring of the cumulative deformation component characteristics, the deformation of the monitoring area mainly points to the outside of the slope and the upstream of the river.

3.2.2. Total Deformation. The total deformation represents the actual deformation distance of the apparent monitoring points. According to Table 2, as of August 8, 2017, the cumulative total deformation of three monitoring points (TP08, TP09, and TP13) is more significant than $200 \mathrm{~mm}$. The TP08 monitoring point has the most considerable deformation $(312.45 \mathrm{~mm})$, and the cumulative total deformation of two monitoring points (TP07 and TP12) is $200 \sim 150 \mathrm{~mm}$. These five monitoring points are mainly distributed in the ridge-like terrain at the top of the slope, which is greatly affected by excavation disturbance and rainfall infiltration.

In summary, since December 24, 2016, with the blasting excavation of the slope below $830 \mathrm{~m}$, all monitored apparent deformation components and total deformations increase sharply, and the deformation rate is accelerated. The deformation generated at this stage accounts for $80 \%$ of the total deformation. After March 25, 2017, the deformation rate decreases significantly with the completion of the excavation, and as of August 8,2017, eight out of the 14 apparent monitoring points converge, and the deformation rate of six points significantly reduces and tends to converge.

3.3. Anchor Stress Monitoring Results. Twenty-six sets of anchor stress meters, numbered R01 R26, were all arranged at the downstream of fault $F_{6}$. Eighteen sets were placed between fault $F_{6}$ and the rear edge slope of the concrete 
TABLE 3: Anchor stress meter monitoring results.

\begin{tabular}{|c|c|c|c|c|c|}
\hline Section & Number & Elevation $(\mathrm{m})$ & Monitoring start time $(\mathrm{yy} / \mathrm{mm} / \mathrm{dd})$ & $17 / 08 / 10$ stress $(\mathrm{MPa})$ & Remarks \\
\hline \multirow{4}{*}{$1-1^{\prime}$} & R01 & 939 & $13 / 09 / 27$ & -8.6 & \\
\hline & R02 & 924 & $13 / 09 / 22$ & $\& 4$ & \\
\hline & R03 & 894 & $13 / 11 / 15$ & -27.3 & \\
\hline & R04 & 864 & $16 / 08 / 14$ & 42.0 & \\
\hline \multirow{4}{*}{$2-2^{\prime}$} & R05 & 939 & $13 / 05 / 05$ & -2.4 & \\
\hline & R06 & 924 & $13 / 05 / 05$ & 29.5 & 15/05/07 damage \\
\hline & R07 & 894 & $13 / 05 / 05$ & -0.4 & 13/07/06 damage \\
\hline & R08 & 864 & $13 / 05 / 05$ & -14.2 & \\
\hline \multirow{4}{*}{$3-3^{\prime}$} & R09 & 939 & $13 / 05 / 05$ & -16.8 & 13/07/06 damage \\
\hline & $\mathrm{R} 10$ & 924 & $13 / 05 / 05$ & -13.1 & \\
\hline & R11 & 894 & $13 / 05 / 05$ & -12.4 & \\
\hline & $\mathrm{R} 12$ & 864 & $13 / 05 / 05$ & -10.7 & \\
\hline \multirow{8}{*}{$4-4^{\prime}$} & $\mathrm{R} 13$ & 924 & $13 / 09 / 22$ & 226.0 & 17/06/21 damage \\
\hline & $\mathrm{R} 14$ & 879 & $16 / 05 / 09$ & 19.7 & \\
\hline & R15 & 849 & $16 / 08 / 20$ & 40.4 & \\
\hline & $\mathrm{R} 16$ & 849 & $16 / 08 / 20$ & 53.0 & \\
\hline & R17 & 849 & $16 / 08 / 20$ & 106.9 & \\
\hline & $\mathrm{R} 18$ & 829 & $17 / 03 / 25$ & 181.8 & \\
\hline & R19 & 829 & $17 / 03 / 25$ & 1.7 & \\
\hline & $\mathrm{R} 20$ & 829 & $17 / 03 / 25$ & 9.9 & \\
\hline \multirow{6}{*}{$5-5^{\prime}$} & $\mathrm{R} 21$ & 849 & $16 / 08 / 14$ & 87.6 & \\
\hline & $\mathrm{R} 22$ & 849 & $16 / 08 / 14$ & 0.5 & \\
\hline & $\mathrm{R} 23$ & 849 & $16 / 08 / 14$ & 283.6 & \\
\hline & $\mathrm{R} 24$ & 829 & $17 / 03 / 25$ & 50.8 & \\
\hline & R25 & 829 & $17 / 03 / 25$ & 16.9 & 13/07/06 damage \\
\hline & $\mathrm{R} 26$ & 829 & $17 / 03 / 25$ & 27.9 & \\
\hline
\end{tabular}

system at $850 \mathrm{~m}$ elevation, and eight sets were at the rear edge slope (Figure 5).

Figure 8 shows the monitoring results of all anchor stress meters, as summarized in Table 3. According to the data analysis, as of August 10, 2017, three monitoring points exceed $150 \mathrm{MPa}$, and the monitoring point R23 of $849 \mathrm{~m}$ elevation detects the most significant stress change, i.e., an increase of $283.6 \mathrm{MPa}$. The measured stress of five anchors is within $150 \sim 30 \mathrm{MPa}$, while the variation of the remaining sensors is less than $30 \mathrm{MPa}$.

According to the stress change curve analysis of all anchor stress meters, the stress change rate of each anchor stress meter increases sharply after blasting excavation of the slope below $830 \mathrm{~m}$ elevation on December 24, 2016. After March 25, 2017, with the blasting excavation stopped, except for the R16 anchor stress whose growth rate is still high, the stress growth rate is significantly reduced. As of August 10, 2017, 23 anchor stress monitoring curves have converged, and the stress growth rate of two anchors has reduced significantly and tends to converge. Only one set of R16 anchors at $829 \mathrm{~m}$ elevation remains at a higher stress growth rate.

To sum up, data from multipoint displacement meters, apparent deformation of the slope, and anchor stress meters showed that the deformation amount and deformation rate of the slope keep relatively large from July 2016 to March 2017. It is the result of the combined effect of high-strength blasting excavation and long-term rainwater infiltration of the slope rock mass in the rainy season. The maximum deformation occurs at the $4-4^{\prime}$ monitoring section, i.e., the protruding ridge topography, followed by the middle area of the slope, and the accumulated deformation amount of the slope behind the concrete system at $850 \mathrm{~m}$ elevation and other areas of the slope is small. At present, the slope deformation of the slope is at the stage of convergence. However, in the subsequent slope engineering, especially after the spillway is put into use, strong water impact and atomized rain infiltration will have a serious impact on the stability of the slope, so continuous monitoring is still required to ensure the stability of the slope.

\section{Deformation Mechanism}

4.1. The Poor Quality of Lithology. The upper cover of the engineering slope is a gently inclined thin layer of dolomite and thick layer dolomite with shale interlayer. The middle and lower part is a transverse thin layer of limestone and dolomite; the rock mass is poor. The fault $F_{6}$, which is an antidip rock mass structure, runs through the entire slope 


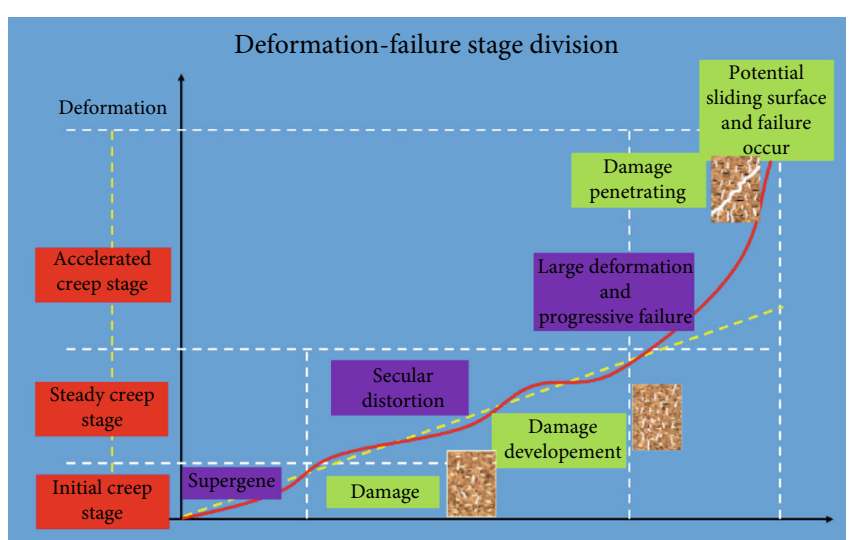

FIGURE 9: Deformation-failure evolution process of slope.

and steeply dip direction into the slope, intersecting the slope at a large angle. The fault $F_{6}$ divides the slope into two parts that form the weak boundary of the lower slope of the fault, which weakens the three-dimensional side restraining effect of the front slope of the flood discharge tunnel on the entire left slope. At the same time, due to the deformation of the downstream slope of fault $F_{6}$, the fault and the lower rock mass squeeze under the action of the self-compression of the weak part of the fault and the deformation slip to the outer side of the slope. Due to the long construction period and the large annual temperature difference in the study area, the rock mass will inevitably be subjected to weathering, which will change the lithology of the slope surface rock mass, reduce the quality of the rock mass, and increase the permeability. The degree of weathering decreases with the depth of the slope, and the depth of weathering varies with the quality of the rock mass, which results in the heterogeneity of the seepage of the slope rock mass.

4.2. Disturbance of Engineering Activities. Although the engineering slope is a high-steep slope, before the excavation, the slope rock mass is in a relatively stable state. The excavation of the project redistributes the stress inside the rock mass. With the gradual expansion of the slope excavation, the rock mass on the slope is subjected to blasting dynamics to generate dynamic damage. On the other hand, the excavation changes the boundary conditions of the slope, and the rock mass undergoes unloading deformation. Part of the strain energy in the rock mass is released, and part of the strain energy is transferred to the deep part of the rock mass, resulting in stress redistribution. Moreover, the deformation of the slope body accompanies the redistribution causing the original structural plane in the rock mass to open and stagger, the expansion of the original joint fissure, or the generation of new cracks, especially in the vicinity of geological weak planes such as faults, soft rock areas, and strong unloading relaxation areas. The combination of new cracks and fault fracture zones generated in the unloading relaxation zone provides convenient conditions for rock mass seepage, and the slope rock mass seepage will vary with the degree of unloading (Figure 9).
4.3. Impact of Rainfall and Atomized Rain. The overall lithology of the slope, coupled with the slope rock mass stress relaxation and deep rock mass cracks caused by engineering disturbance and stress redistribution, provides convenient conditions for rainwater infiltration. Rain infiltrates along the cracks on the slope surface, weakening the mechanical properties of rock and soil. With the continuous heavy rainfall in the rainy season, seepage is formed in the rock mass above the depth of rainfall infiltration, and saturated runoff is formed on the surface of the slope. The infiltration of rainfall and atomized rain water forms a saturated zone that is detrimental to stability and unfavorable in the rock mass of the slope. Although the current saturation zone is not deep, it still causes the water level of the infiltration line on the surface of the slope to change. Especially the atomized rain produced by the waterfall is closer to the fault $F_{6}$, the permeability of the fault fracture zone is stronger, and the overall quality of the slope rock mass is poor. The infiltration of rainwater increases the pore water pressure on the rock mass and reduces the effective stress, and the rock mass and rock mass structural surface are softened by the influence of groundwater. The mechanical properties of rock masses and structural planes change, which will have a very adverse effect on the slope stability.

In summary, due to the influence of stratum lithology, excavation disturbance, rainfall, and atomized rain infiltration, part of the apparent monitoring data of the slope surface suddenly increased from November 2016. As of the end of March 2017, the excavation above $806 \mathrm{~m}$ elevation was completed. The apparent monitoring data reveal that the deformation rate of the slope is still relatively fast, and the conventional monitoring bolt is subjected to a large force. In order to control the continuous large deformation of the slope, the excavation of the lower part of the slope was stopped on April 1, 2017. The excavated slope was systematically supported in time, and then the deformation rate of the slope slowed down. After filling the plunge pool with water on June 22, 2017, the excavation and support works of the slope were completely stopped. On October 26,2017 , the plunge pool was pumped after the flood season, and the excavation construction of the slope below $806 \mathrm{~m}$ fully started. Given the large deformation of the slope caused by the excavation between the 850 and $806 \mathrm{~m}$ elevation and considering the impact of strong atomized rain after the normal use of the spillway tunnel, flood discharge impact and atomized rain infiltration will be the most important factors affecting slope stability. In order to better understand the slope deformation law and avoid large deformation caused by the excavation of elevation below $806 \mathrm{~m}$ and to guarantee the safety and stability of the slope and integrate monitoring, early warning, reinforcement, and control, it is urgent to establish an early warning criterion and early warning mode suitable for the landslide monitoring of Wudongde Hydropower Station.

\section{New Technology for Preventing and Monitoring the Slope Deformation}

Although the left side high slope of the Wudongde flood discharge tunnel does not currently form a sliding surface, the 

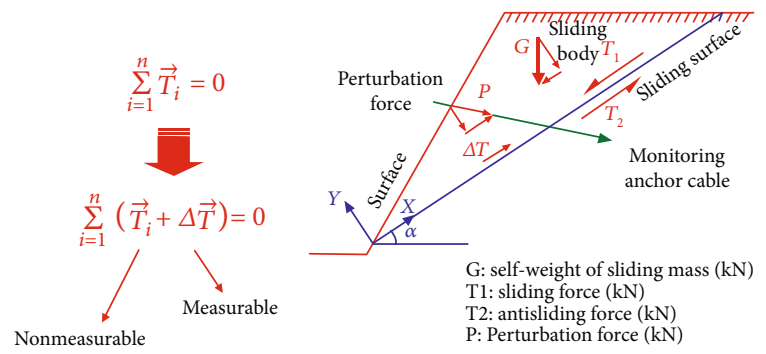

FIGURE 10: Schematic diagram of landslide measurable mechanical system.

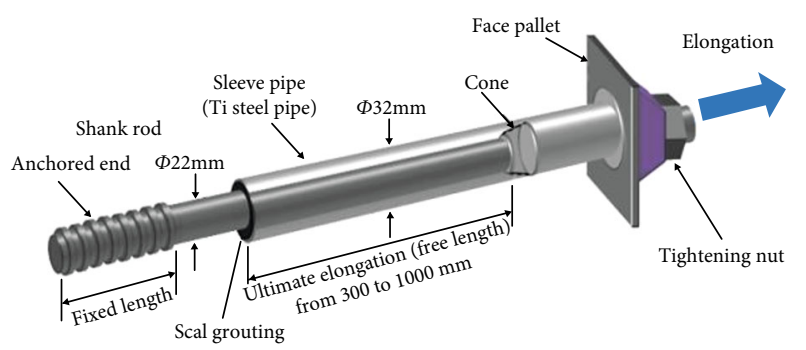

FIgURe 11: Structure diagram of CRLD cable.

excavation inevitably changes the stress distribution inside the slope body. At the same time, the deformation evolution of the slope is an irreversible process of the development of microfracture inside the rock mass, the weakening of the macromechanical characteristics of the rock mass, and the formation, development, and penetration of the sliding surface. Moreover, these new cracks caused by the construction of slope engineering will facilitate the infiltration of rainfall, especially the intense atomization rain caused by flood discharge. This will also be the most important factor affecting the stability of the hydropower station. At present, because the conventional anchor cable is easy to break during the process of slope deformation, the evolution law of the sliding force inside the slope is difficult to monitor. It is challenging to meet the requirements of landslide monitoring only by shallow displacement and deformation monitoring. Moreover, the conventional monitoring equipment on the slope surface is susceptible to failure due to the effects of strong atomizing rain. Therefore, it is necessary to consider the remote monitoring and early warning system of the slope anchor force developed by the State Key Laboratory of Geotechnical Mechanics and Underground Engineering of China University of Mining and Technology (Beijing) for real-time remote intelligent monitoring of the left side slope of Wudongde flood discharge tunnel.

5.1. Landslide Remote Monitoring and Early Warning System. Based on the monitoring principle of anchor cable force and the working principle of constant resistance large deformation anchor cable, Professor He Manchao developed a landslide monitoring and early warning system based on anchor cable force measurement [39]. The system is based on the principle that "sliding force greater than shear strength is a sufficient and necessary condition for landslide generation."

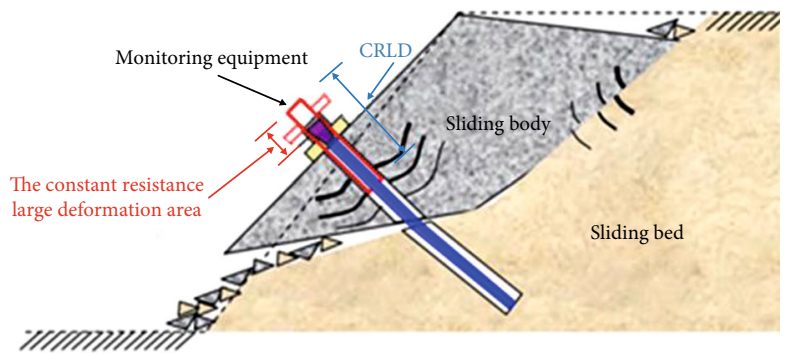

FIGURE 12: Reinforce and monitoring principle of CRLD cable.

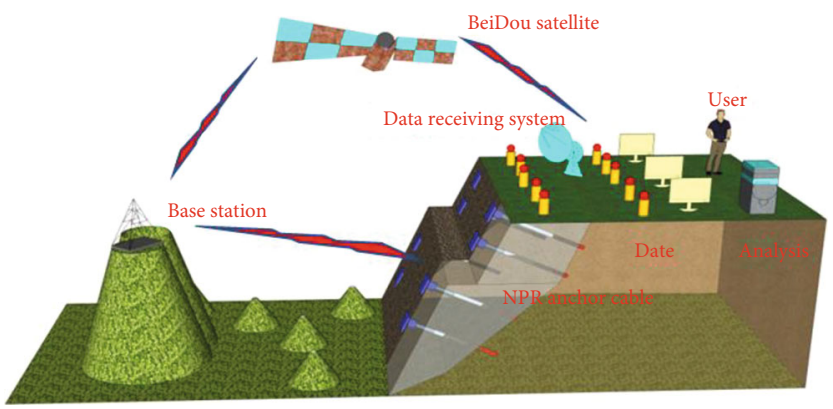

FIgURE 13: The principle of system operation.

The indirect measurement of the sliding force on the potential sliding surface is achieved by directly measuring and monitoring the axial force on the cable, thus breaking the bottleneck of traditional deformation monitoring. Also, the monitoring and early warning of the deep anchor cable force is realized for the first time.

\subsubsection{Principle of Anchor Cable Force Remote Monitoring.} The landslide will only occur if the sliding force is greater than the antisliding force. By considering the mechanical system of a natural landslide, three main forces are acting on it, i.e., sliding force $\left(T_{1}\right)$, antisliding force $\left(T_{2}\right)$, and self-weight of sliding mass $(G)$. In the natural state, the sliding force and antisliding force on the sliding surface are in equilibrium, i.e., $T_{1} \leq T_{2}$, and the slope is stable. However, when the external or internal factors affecting the slope stability change, the original equilibrium state breaks, and the stress in the landslide body redistributes. When $T_{1}>T_{2}$, the slope is unstable. Therefore, it is only necessary to accurately measure $T_{1}$ and $T_{2}$ to judge the changing state of stress in the landslide body and predict the occurrence time and scale of landslide disaster in advance. In order to measure $T_{1}$ and $T_{2}$, the magnitude of sliding force $T_{1}$ can be indirectly calculated through direct monitoring of disturbing force $P$ after the artificial measurable force $P$ is introduced. Figure 10 shows the complex mechanical system composed of the natural mechanical system and an artificial mechanical system.

5.1.2. Structure of Constant-Resistance Large-Deformation Anchor Cable and Working Principle. As a composite structure type stretchable anchor cable, the proposed ConstantResistance Large-Deformation (CRLD) anchor cable mainly consists of rod body, constant resistance body, constant 
TABLE 4: Warning level and warning criteria.

\begin{tabular}{|c|c|c|c|c|c|}
\hline Warning level & Danger forecast & $\begin{array}{c}\text { Level } 1 \text { criteria: } \\
\text { cumulative increment } T / \mathrm{t}\end{array}$ & \multicolumn{3}{|c|}{ Secondary criterion: daily slip of sliding force $\Delta T / \mathrm{t}$} \\
\hline Blue & Stability & $0 \sim 50$ & $10 \sim 20$ up to yellow & \multirow{4}{*}{$20 \sim 35$ up to orange } & \multirow{4}{*}{$>35$ up to red } \\
\hline Yellow & Substable & $50 \sim 120$ & & & \\
\hline Orange & Near slip & $120 \sim 160$ & & & \\
\hline Red & Impending slide & $>160$ & & & \\
\hline
\end{tabular}

Anchor force $T=T_{n}-T_{0}$; sliding force increment $\Delta T=T_{n}-T_{n-1}$; initial prestress $T_{0}=30 \mathrm{t}$.

resistance sleeve, pallet, and nut (Figure 11). The constant resistance body and the constant resistance sleeve together form a constant resistance device to provide constant support resistance for the anchor cable.

When landslide occurs, with the slow release of deformation energy in the slope rock mass, the sliding body and sliding bed move relatively along the sliding surface. When the deformation energy of the rock mass exceeds the designed constant resistance, the constant resistance body frictionally slides along the inner wall of the constant resistance sleeve. The CRLD anchor cable stretches axially along with the large deformation of the slope rock mass and absorbs the energy generated by the slow landslide deformation (Figure 12). It avoids the failure of conventional monitoring anchor cable due to excessive deformation, meeting the targets of advanced monitoring and early warning for the landslide.

\subsubsection{Structure of the Landslide Remote Monitoring and Early} Warning System. The landslide remote monitoring and early warning system consists of indoor and on-site equipment. The indoor monitoring equipment includes a data receiving-processing-analysis system, $3 \mathrm{~S}$ maps of monitoring point target areas, a 3D monitoring engineering image search system, and some auxiliary analysis software. The on-site monitoring equipment consists of BeiDou satellite receiving equipment, data processing system, and information display system. Figure 13 shows the schematics of the system's working principle.

5.1.4. Landslide Monitoring and Warning Criteria. In order to improve the monitoring accuracy, this study establishes a landslide monitoring and early warning model. The model mainly relies on system equations and empirical equations. Through statistical analysis of the monitoring data of 354 existing monitoring systems in the past ten years and the results of indoor physical model experiments, a landslide four-level early warning mode is established. The model classifies the degree of hazard of the slope into four levels described by different colors, i.e., red (imminent slip early warning), orange (near slip early warning), yellow (metastable early warning), and blue (stable). Table 4 summarizes the specific grades and early warning criteria.

5.2. Monitoring Point Layout. Taking full account of the slope deformation trend, topography, rock lithology, geological structure, spatial distribution of the fracture, excavation

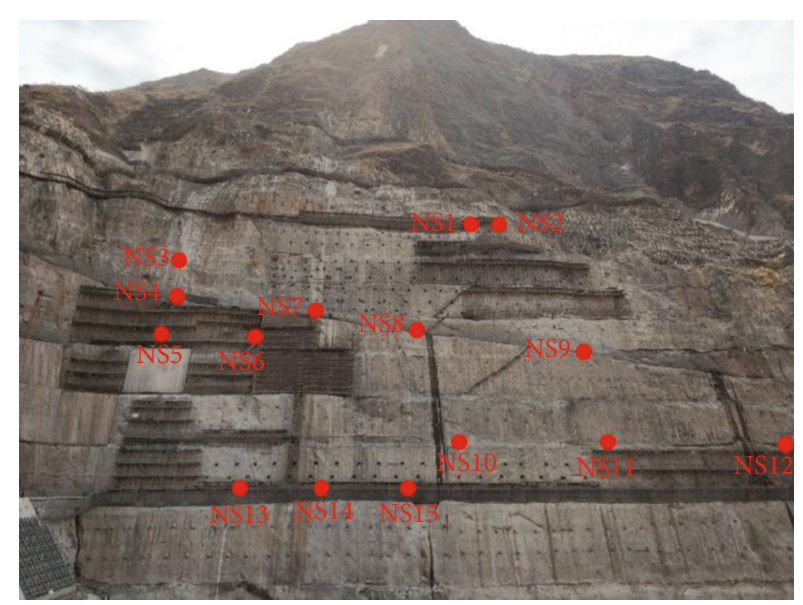

FIGURE 14: Layout of on-site monitoring points.

method, and schedule combined with the technical requirements of slope anchor cable force monitoring. A total of 15 monitoring points (NS1 NS15) were arranged within the scope of the engineering slope. The distribution of monitoring points is shown in Figure 14.

5.3. Monitoring Results and Analysis. From April 25, 2018, to October 18, 2018, eight sets of remote monitoring and early warning systems have been installed on the left side slope of the flood discharge tunnel, and the high slope has been continuously monitored for 24 hours. At present, about 14,000 series of data have been collected (Figure 15), which provides important data for monitoring the deformation and evolution characteristics of slopes and early warning.

Through the analysis of the monitoring curve and monitoring data that have been received so far, $75 \%$ of the monitoring curve is in a horizontal state or an approximate horizontal state, indicating that the slope is in a stable state. Also, the NS1 monitoring curve contains some unstable data, while the NS2 curve has a slow downward trend, indicating that the top slope is currently in a relatively stable state.

From a macroperspective, as the slope project is nearing completion, most of the slopes are in a stable state. However, as the spillway tunnel is put into use, the strong water impact and the infiltration of atomized rain generated by the flood discharge will have a long-term and continuous impact on the stability of the slope. Therefore, long-term real-time monitoring of slope stability is still needed. 


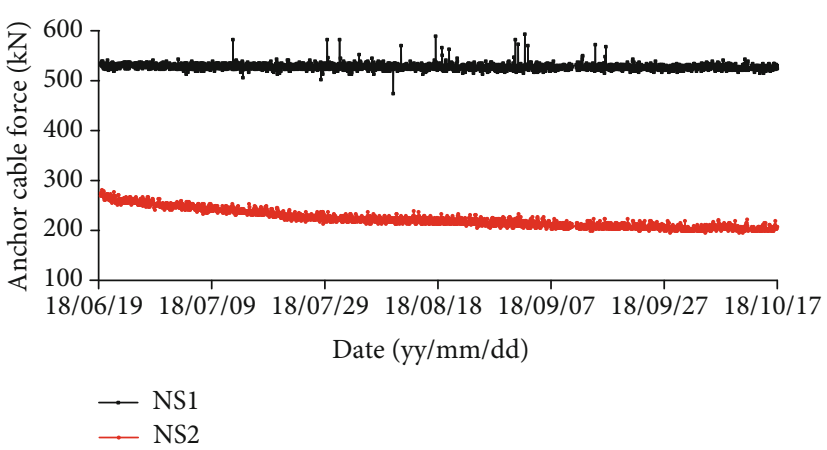

(a) NS1 and NS2 monitoring points

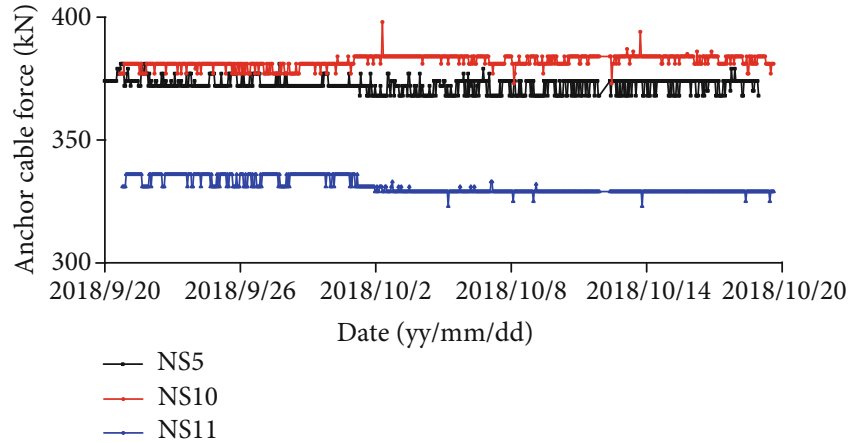

(b) NS5, NS10, and NS11 monitoring points

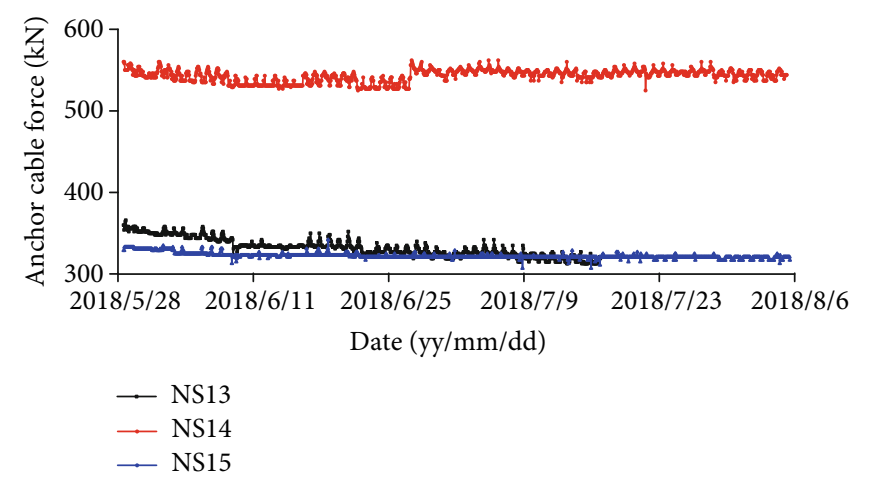

(c) NS13, NS14, and NS15 monitoring points

FIGURE 15: Curves of anchor cable force.

\section{Conclusions}

Based on the above analysis, a few conclusions can be drawn:

(1) The data from multipoint displacement meters, the apparent deformation, and the anchor stress meters all show that the deformation amount and deformation rate of the slope are relatively large during the construction of the slope. It is the result of the combined effect of high-strength blasting excavation and long-term rainwater infiltration of the slope rock mass in the rainy season. The maximum deformation amount is located at the $4-4^{\prime}$ deformation monitoring section, especially near the top of the opening line at this section, followed by the middle area of the slope

(2) Through comprehensive analysis, the main reason for the large deformation of the slope is that after the excavation of the slope, the slope rock mass will inevitably be affected by weathering and unloading. In addition, the overall quality of the slope rock mass is poor. Weathering changes the lithology of the rock mass on the surface of the slope, reducing the quality of the rock mass and enhancing the permeability. The degree of weathering decreases with the depth of the slope, and the depth of weathering varies according to the quality of the rock mass. The unloading relaxation of rock mass changes the original stress field of the slope, and different unloading degrees cause the cracks in the slope rock mass to open, slip, and expand to different degrees. Rock mass seepage is closely related to rock mass fissures. The degree of unloading decreases with the depth of the slope, and the degree of unloading varies with the quality of the rock mass, resulting in heterogeneity of the seepage of the slope rock mass

(3) The newly created cracks and fault fracture zones in the weathering and unloading relaxation zone provide convenient conditions for rainfall and atomized rain infiltration. Rainfall and atomized rainwater infiltrate along the slope surface, forming a seepage field in the slope body, especially in areas with poor rock quality, such as near the fault fracture zone and the top ridged terrain area of the slope. The long-term infiltration of rainwater weakens the rock mass parameters, weakens the strength of the rock mass structural surface, increases the water pressure in the fissures, and causes large deformation of the slope

(4) The impact of water flow and the infiltration of atomized rain caused by flood discharge will be the most important factors affecting the stability of this slope in the future. Therefore, the landslide anchor cable force remote monitoring system based on the constant resistance and large deformation anchor cable is used to monitor the stability of the slope. The 
current monitoring results show that the slope is in a stable state. The research results will provide a scientific basis for the stability control of high and steep slopes of hydropower stations in the future

\section{Conflicts of Interest}

No conflict of interest exists in the submission of this manuscript.

\section{Authors' Contributions}

The manuscript was approved by all authors for publication.

\section{Acknowledgments}

This study was supported by the Zhejiang Province Key R\&D Projects (No. 2019C03104) and the Fundamental Research Funds for the Central Universities, SCUT (No. 2015QB02).

\section{References}

[1] C. R. J. Kilburn and D. N. Petley, "Forecasting giant, catastrophic slope collapse: lessons from Vajont, Northern Italy," Geomorphology, vol. 54, no. 1-2, pp. 21-32, 2003.

[2] C. Zhu, M. He, M. Karakus, X. Cui, and Z. Tao, "Investigating toppling failure mechanism of anti-dip layered slope due to excavation by physical modelling," Rock Mechanics and Rock Engineering, 2020.

[3] J. Xu, A. Haque, W. Gong et al., "Experimental study on the bearing mechanisms of rock-socketed piles in soft rock based on micro X-ray CT analysis," Rock Mechanics and Rock Engineering, vol. 53, no. 8, pp. 3395-3416, 2020.

[4] N. Jiang, C. X. Wang, H. Y. Pan, D. Yin, and J. Ma, "Modeling study on the influence of the strip filling mining sequence on mining-induced failure," Energy Science \& Engineering, vol. 8, no. 6, pp. 2239-2255, 2020.

[5] C. X. Wang, B. T. Shen, J. T. Chen et al., "Compression characteristics of filling gangue and simulation of mining with gangue backfilling: an experimental investigation," Geomechanics and Engineering, vol. 20, no. 6, pp. 485-495, 2020.

[6] Q. Yin, G. W. Ma, H. W. Jing et al., "Hydraulic properties of 3D rough-walled fractures during shearing: an experimental study," Journal of Hydrology, vol. 555, pp. 169-184, 2017.

[7] H. Huang, T. Babadagli, X. Chen, H. Li, and Y. Zhang, "Performance comparison of novel chemical agents for mitigating water-blocking problem in tight gas sandstones," SPE Reservoir Evaluation \& Engineering, 2020.

[8] Y. Zhang, S. Cao, N. Zhang, and C. Zhao, "The application of short-wall block backfill mining to preserve surface water resources in northwest China," Journal of Cleaner Production, vol. 261, article 121232, 2020.

[9] J. Cai, N. Ju, R. Huang et al., "Mechanism of toppling and deformation in hard rock slope: a case of bank slope of Hydropower Station, Qinghai Province, China," Journal of Mountain Science, vol. 16, no. 4, pp. 924-934, 2019.

[10] X. Wang, C. Liu, S. Chen, L. Chen, K. Li, and N. Liu, "Impact of coal sector's de-capacity policy on coal price," Applied Energy, vol. 265, article 114802, 2020.

[11] Y. X. Xiao, X. T. Feng, G. L. Feng, H. J. Liu, Q. Jiang, and S. L. Qiu, "Mechanism of evolution of stress-structure controlled collapse of surrounding rock in caverns: a case study from the Baihetan hydropower station in China," Tunnelling and Underground Space Technology, vol. 51, pp. 56-67, 2016.

[12] F. Dai, B. Li, N. Xu, G. Meng, J. Wu, and Y. Fan, "Microseismic monitoring of the left bank slope at the Baihetan hydropower station, China," Rock Mechanics and Rock Engineering, vol. 50, no. 1, pp. 225-232, 2017.

[13] N. Xu, J. Wu, F. Dai, Y. Fan, T. Li, and B. Li, "Comprehensive evaluation of the stability of the left-bank slope at the Baihetan hydropower station in southwest China," Bulletin of Engineering Geology and the Environment, vol. 77, no. 4, pp. 15671588, 2018.

[14] Z. Zhang, X. Huang, W. Liu, and L. Wang, "Study on the hydraulic parameters of Woshaxi landslide soils during water level drawdown of three gorges reservoir," Geofluids, vol. 2020, Article ID 6283791, 14 pages, 2020.

[15] C. Meisina, M. Bittelli, R. Valentino, M. Bordoni, and R. Tomás-Jover, "Advances in shallow landslide hydrology and triggering mechanisms: a multidisciplinary approach," Geofluids, vol. 2019, Article ID 1607684, 2 pages, 2019.

[16] A. Wayllace, B. Thunder, N. Lu, A. Khan, and J. W. Godt, "Hydrological behavior of an infiltration-induced landslide in Colorado, USA," Geofluids, vol. 2019, Article ID 1659303, 14 pages, 2019.

[17] B. Han, B. Tong, J. Yan, C. Yin, L. Chen, and D. Li, "The monitoring-based analysis on deformation-controlling factors and slope stability of reservoir landslide: Hongyanzi landslide in the southwest of China," Geofluids, vol. 2018, 7391514 pages, 2018.

[18] N. Zhang, W. Liu, Y. Zhang, P. Shan, and X. Shi, "Microscopic pore structure of surrounding rock for underground strategic petroleum reserve (SPR) caverns in bedded rock salt," Energies, vol. 13, no. 7, article 1565, 2020.

[19] P. Shan and X. Lai, “An associated evaluation methodology of initial stress level of coal-rock masses in steeply inclined coal seams, Urumchi coal field, China," Engineering Computations, vol. 37, no. 6, pp. 2177-2192, 2020.

[20] H. Y. Pan, D. W. Yin, N. Jiang, and Z. G. Xia, “Crack initiation behaviors of granite specimens containing crossing-doubleflaws with different lengths under uniaxial loading," Advances in Civil Engineering, vol. 2020, pp. 1-13, 2020.

[21] Q. Yin, R. Liu, H. Jing, H. Su, L. Yu, and L. He, "Experimental study of nonlinear flow behaviors through fractured rock samples after High-Temperature exposure," Rock Mechanics and Rock Engineering, vol. 52, no. 9, pp. 2963-2983, 2019.

[22] Q. Yin, H. Jing, H. Su, and H. Zhao, "Experimental study on mechanical properties and anchorage performances of rock mass in the fault fracture zone," International Journal of Geomechanics, vol. 18, no. 7, article 04018067, 2018.

[23] X. Wang, W. Yuan, Y. T. Yan, and X. Zhang, "Scale effect of mechanical properties of jointed rock mass: a numerical study based on particle flow code," Geomechanics and Engineering, vol. 21, no. 3, pp. 259-268, 2020.

[24] D. Liu, Z. Gu, R. Liang et al., "Impacts of pore-throat system on fractal characterization of tight sandstones," Geofluids, vol. 2020, Article ID 4941501, 17 pages, 2020.

[25] S. C. Hu, Y. L. Tan, H. Zhou et al., "Anisotropic modeling of layered rocks incorporating planes of weakness and volumetric stress," Energy Science \& Engineering, vol. 8, no. 3, pp. 789803,2020 . 
[26] D. Z. Ren, D. S. Zhou, D. K. Liu, F. Dong, S. Ma, and H. Huang, "Formation mechanism of the Upper Triassic Yanchang Formation tight sandstone reservoir in Ordos Basin-Take Chang 6 reservoir in Jiyuan oil field as an example," Journal of Petroleum Science and Engineering, vol. 178, pp. 497-505, 2019.

[27] J. Chen, J. Zhao, S. Zhang, Y. Zhang, F. Yang, and M. Li, “An experimental and analytical research on the evolution of mining cracks in deep floor rock mass," Pure and Applied Geophysics, 2020.

[28] J. Wang, Y. Zhang, Z. Qin, S. G. Song, and P. Lin, “Analysis method of water inrush for tunnels with damaged waterresisting rock mass based on finite element method-smooth particle hydrodynamics coupling," Computers and Geotechnics, vol. 126, article 103725, 2020.

[29] F. Q. Ren, C. Zhu, and M. C. He, "Moment tensor analysis of acoustic emissions for cracking mechanisms during schist strain burst," Rock Mechanics and Rock Engineering, vol. 53, no. 1, pp. 153-170, 2020.

[30] J. Xu, G. Dai, W. Gong, Q. Zhang, A. Haque, and R. P. Gamage, "A review of research on the shaft resistance of rock-socketed piles," Acta Geotechnica, 2020.

[31] G. Feng, X. C. Wang, M. Wang, and Y. Kang, "Experimental investigation of thermal cycling effect on fracture characteristics of granite in a geothermal-energy reservoir," Engineering Fracture Mechanics, vol. 235, article 107180, 2020.

[32] G. Feng, Y. Kang, X. C. Wang, Y. Hu, and X. Li, "Investigation on the failure characteristics and fracture classification of shale under Brazilian test conditions," Rock Mechanics and Rock Engineering, vol. 53, no. 7, pp. 3325-3340, 2020.

[33] Y. Zhang, H. Li, Q. Sheng, K. Wu, and G. Chen, "Real time remote monitoring and pre-warning system for highway landslide in mountain area," Journal of Environmental Sciences, vol. 23, pp. S100-S105, 2011.

[34] Y. Yin, H. Wang, Y. Gao, and X. Li, "Real-time monitoring and early warning of landslides at relocated Wushan Town, the Three Gorges Reservoir, China," Landslides, vol. 7, no. 3, pp. 339-349, 2010.

[35] O. A. Conte and R. A. Coffman, "Slope stability monitoring using remote sensing techniques," in GeoCongress 2012: State of the Art and Practice in Geotechnical Engineering, pp. 3060-3068, Oakland, California, USA, March 2012.

[36] C. Atzeni, M. Barla, M. Pieraccini, and F. Antolini, "Early warning monitoring of natural and engineered slopes with ground-based synthetic-aperture radar," Rock Mechanics and Rock Engineering, vol. 48, no. 1, pp. 235-246, 2015.

[37] P. K. Miller, M. Vessely, L. D. Olson, and Y. Tinkey, "Slope stability and rock-fall monitoring with a remote interferometric radar system," in Geo-Congress 2013: Stability and Performance of Slopes and Embankments III, pp. 304-318, San Diego, California, USA, February 2013.

[38] G. J. Dick, E. Eberhardt, A. G. Cabrejo-Liévano, D. Stead, and N. D. Rose, "Development of an early-warning time-of-failure analysis methodology for open-pit mine slopes utilizing ground-based slope stability radar monitoring data," Canadian Geotechnical Journal, vol. 52, no. 4, pp. 515-529, 2015.

[39] L. Zan, G. Latini, E. Piscina, G. Polloni, and P. Baldelli, "Landslides early warning monitoring system," in IEEE International Geoscience and Remote Sensing Symposium, pp. 188-190, Toronto, Ontario, Canada, June 2002.

[40] N. W. Xu, C. A. Tang, L. C. Li et al., "Microseismic monitoring and stability analysis of the left bank slope in Jinping first stage hydropower station in southwestern China," International Journal of Rock Mechanics and Mining Sciences, vol. 48, no. 6, pp. 950-963, 2011.

[41] M. He, W. Gong, J. Wang et al., "Development of a novel energy-absorbing bolt with extraordinarily large elongation and constant resistance," International Journal of Rock Mechanics and Mining Sciences, vol. 67, pp. 29-42, 2014.

[42] Z. Tao, H. Zhang, Y. Chen, and C. Jiang, "Support principles of NPR bolt/cable and control techniques of large-deformation disasters," International Journal of Mining Science and Technology, vol. 26, no. 6, pp. 967-973, 2016.

[43] M. C. HE, Z. G. TAO, and B. ZHANG, "Application of remote monitoring technology in landslides in the Luoshan mining area," Mining Science and Technology (China), vol. 19, no. 5, pp. 609-614, 2009.

[44] X. Yang, D. Hou, Z. Tao, Y. Peng, and H. Shi, "Stability and remote real-time monitoring of the slope slide body in the Luoshan mining area," International Journal of Mining Science and Technology, vol. 25, no. 5, pp. 761-765, 2015.

[45] Z. Tao, Y. Wang, C. Zhu, H. Xu, G. Li, and M. He, "Mechanical evolution of constant resistance and large deformation anchor cables and their application in landslide monitoring," Bulletin of Engineering Geology and the Environment, vol. 78, no. 7, pp. 4787-4803, 2019. 